\title{
Areas and factors associated with patients' dissatisfaction with glaucoma care
}

\author{
This article was published in the following Dove Press journal: \\ Clinical Ophthalmology \\ 13 October 2017 \\ Number of times this article has been viewed
}

\author{
Valencia Hui Xian Foo' \\ Sarah En Mei Tan ${ }^{2}$ \\ David Ziyou Chen ${ }^{3}$ \\ Shamira A Perera ${ }^{1,4}$ \\ Charumathi Sabayanagam ${ }^{4,5}$ \\ Eva Katie Fenwick ${ }^{4,5}$ \\ Tina T Wong ${ }^{1,4,5}$ \\ Ecosse L Lamoureux ${ }^{4-6}$ \\ 'Singapore National Eye Centre, \\ Singapore; ${ }^{2}$ Tan Tock Seng Hospital, \\ Singapore; ${ }^{3}$ Department of \\ Ophthalmology, National University \\ of Singapore and National University \\ Health System, Singapore; ${ }^{4}$ Singapore \\ Eye Research Institute, Singapore \\ National Eye Centre, Singapore; \\ ${ }^{5}$ Centre for Quantitative Medicine, \\ Duke-NUS Medical School, Singapore; \\ ${ }^{6}$ Centre for Eye Research Australia, \\ University of Melbourne, Melbourne, \\ VIC, Australia
}

Objective: The aim of this study was to evaluate patients' dissatisfaction with overall and specific aspects of a tertiary glaucoma service and to determine their independent factors, including intraocular pressure (IOP) and visual acuity (VA).

Methods: Patients, aged $\geq 21$ years, from a specialist glaucoma service in a tertiary eye hospital in Singapore for at least 6 months, were recruited for this cross-sectional study between March and June 2014. All consenting patients completed a 7-area glaucoma-specific satisfaction questionnaire and one item related to satisfaction with overall glaucoma care. We determined the top three areas of dissatisfaction and overall dissatisfaction with the glaucoma service. We also explored the independent factors associated with overall and specific areas of patients' dissatisfaction with their glaucoma care, including VA and IOP by using logistic regression models.

Results: Of the 518 patients recruited, 438 (84.6\%) patients completed the study. Patients' dissatisfaction with the overall glaucoma service was $7.5 \%$. The three areas of glaucoma service with the highest dissatisfaction rates were as follows: 1) explanation of test results $(24.8 \%)$; 2) explanation of glaucoma complications (23.7\%); and 3) advice on managing glaucoma $(23.5 \%)$. Patients who were dissatisfied with the overall service had a worse mean VA compared with satisfied patients (logarithm of the minimum angle of resolution $=0.41 \pm 0.43$ vs $0.27 \pm 0.49$, $p=0.005)$, whereas mean IOP remained well-controlled in both the groups $(13.55 \pm 2.46 \mathrm{mmHg}$ vs $14.82 \pm 2.86 \mathrm{mmHg}, p=0.014)$. In adjusted models, factors associated with overall dissatisfaction with glaucoma care included a pre-university education and above (odds ratio $[\mathrm{OR}]=8.06,95 \%$ $\mathrm{CI}=1.57-41.27)$ and lower IOP $(\mathrm{OR}=0.83,95 \% \mathrm{CI}=0.71-0.98)$.

Conclusion: Although less than one tenth of glaucoma patients were dissatisfied with the overall glaucoma service, one in four patients were dissatisfied with three specific aspects of care. A lower IOP, ironically, and education level were associated with overall dissatisfaction. Improving patients' understanding of glaucoma test results, glaucoma complications, and disease management may increase patient satisfaction levels.

Keywords: physician-patient relations, perception, attitude to health, surveys and questionnaires, quality of health care

\section{Introduction}

As a leading cause of irreversible blindness worldwide, glaucoma affects $>60.5$ million people globally. ${ }^{1}$ Damage to the optic nerve can be prevented in glaucoma patients by effective reduction of intraocular pressure (IOP) through compliance with treatment and regular monitoring at clinical follow-ups. As with other chronic but symptomless conditions, patients' satisfaction with their care is acknowledged to be crucial in contributing to better medical outcomes, adherence with treatment regimens, and cooperation with medical practitioners. ${ }^{2-7}$ For example, a growing number of studies have shown the association of type 2 diabetic patient satisfaction with better HbAlc
Correspondence: Ecosse L Lamoureux Duke-NUS Medical School, National University of Singapore, 20 College Rd, Level 6, Singapore 169856 Email ecosse.lamoureux@duke-nus.edu.sg
Clinical Ophthalmology 2017:1 I 1849-1857

1849

Dovepress if in 0

http://dx,doi.org/10.2147/OPTH.S138668 (c) (i) (-) 2017 Foo et al. This work is published and licensed by Dove Medical Press limited. The full terms of this license are available at https://www.dovepress.com/terms.php cc. hereby accept the Terms. Non-commercial uses of the work are permitted without any further permission from Dove Medical Press Limited, provided the work is properly attributed. For permission for commercial use of this work, please see paragraphs 4.2 and 5 of our Terms (https://www.dovepress.com/terms.php). 
levels. ${ }^{8,9}$ In addition, patients' greater satisfaction with their cardiac care for those with all forms of atherosclerotic cardiac diseases has been shown to be associated with greater adherence and completion rates to their cardiac rehabilitation, greater physical activity, and lower depressive symptoms at discharge. ${ }^{10}$ However, an earlier study has also noted inconsistent findings where better clinical outcomes were not associated with higher patient satisfaction scores. ${ }^{11}$

Considering the lifelong dependence on treatment, it is important to establish the quality of glaucoma services provided and evaluate patients' overall dissatisfaction with their glaucoma care and its relationship not just with IOP, but also with visual acuity (VA) and clinical and personal parameters. This would help to evaluate associations with patient dissatisfaction and work on key areas to reduce further noncompliance rates with their follow-up care and treatment regimens, especially for a disease to which earlier studies have revealed poor compliance to be a persistent problem for many glaucoma patients. ${ }^{12-15}$ Earlier work on dissatisfaction with holistic glaucoma care is scant where most studies have evaluated satisfaction mainly with topical medication ${ }^{15-19}$ as well as visual field testing. ${ }^{20}$

In this study, we determined the rates and independent risk factors of overall and domain-specific patient dissatisfaction levels with the glaucoma service at the largest tertiary eye hospital in Singapore.

\section{Methods}

\section{Study population}

This cross-sectional study involved 518 patients recruited from a glaucoma outpatient clinic at the Singapore National Eye Centre (SNEC) from March to June 2014. The inclusion criteria were the following: 1) a diagnosis of any type of glaucoma (including primary open-angle glaucoma [POAG], angle-closure glaucoma, normal tension glaucoma, secondary glaucoma, congenital glaucoma, inflammatory glaucoma, narrow-angle glaucoma following cataract surgery, juvenile glaucoma, exfoliative glaucoma, or pigmentary glaucoma); 2 ) regular follow-up with the glaucoma service for at least 6 months; 3) having started on ocular anti-hypertensives; and 4) being at least 21 years old. The study was approved by the Institutional Review Board of Singapore Health Services and adhered to the tenets of the Declaration of Helsinki. Written informed consent was obtained from all study patients.

\section{Assessment of outcomes}

\section{Patient satisfaction instrument}

The glaucoma satisfaction survey was developed in-house. Questions were based on satisfaction assessed on 7 specific aspects of glaucoma service derived from discussions with glaucoma specialists and patients randomly approached during glaucoma clinic, which highlighted essential aspects of the patients' longitudinal experience with care. There were 8 questions in total, with one question each on "clinicianpatient relationship," "glaucoma explanation," "test results explanation," "glaucoma complications explanation," "glaucoma management explanation," "consultation time," and "glaucoma eye drops purpose," and "overall glaucoma care received" (Figure S1). We measured satisfaction for each question via a dichotomized response scale consisting of "satisfied" and "dissatisfied."

\section{Clinical assessment}

The best-corrected VA (BCVA) and IOP measurements (endpoint data) of their clinic visit at the time of study recruitment were collected. BCVA was assessed at 6 feet, documented in Snellen value, and converted to logarithm of the minimum angle of resolution (LogMAR). IOP was measured by using Goldmann applanation tonometry. As BCVA may be confounded by other ocular comorbidities, we adjusted for the presence of other ocular conditions in our analyses.

\section{Sociodemographic and ocular health data}

Sociodemographic and medical information and ocular health data were collected from medical records. Sociodemographic information included age, gender, ethnicity (ie, Chinese, Malay, and Indian), annual income, education level, and medical information including comorbidities. Ocular health information included the type of glaucoma, glaucoma severity, duration of glaucoma follow-up, history of any laser treatment and surgical treatment, and presence of other ocular comorbidities, which could confound BCVA.

\section{Glaucoma}

The severity of glaucoma was defined as the mean deviation (MD) of the participants' most recent reliable Humphrey visual field test, in line with the Glaucoma Staging System $^{21}$ - Stage 0: ocular hypertension/earliest glaucoma (MD $>0.00)$; Stage 1: early glaucoma $(\mathrm{MD}=-0.00$ to -6.00$)$; Stage 2: moderate glaucoma $(\mathrm{MD}=-6.01$ to -12.00$)$; Stage 3: severe glaucoma $(\mathrm{MD}=-12.01$ to -20.00$)$; Stage 4: advanced glaucoma ( $\mathrm{MD}=-20.01$ or worse); and Stage 5: end stage. The visual field tests were conducted by using the Humphrey Clinical Visual Field Analyzer II (Carl Zeiss Meditec Inc., Dublin, CA, USA) set for the central 24-2 threshold test, size III white stimulus, and Swedish interactive threshold algorithm standard strategy. Reliability criteria for the test were taken to be $<20 \%$ fixation losses and $<33 \%$ 
false-negative and false-positive errors each. Patients also completed the following validated questionnaires - General Anxiety Disorder (GAD)-7 and Patient Health Questionnaire (PHQ)-9.

\section{Anxiety}

Previous studies have shown that POAG is related to anxiety and depression in patients ${ }^{22}$ and that psychiatric illnesses could concurrently affect satisfaction levels with the service. The GAD-7 questionnaire ${ }^{23}$ provides a measure of the severity of generalized anxiety disorder. The GAD-7 score is calculated by assigning scores of $0,1,2$, and 3 , to the response categories of "not at all," "several days," "more than half the days," and "nearly every day," respectively, and by adding the scores for the 7 questions. Scores of 5, 10, and 15 are used as the cutoff points for mild, moderate, and severe anxiety, respectively. Further psychiatric evaluation is recommended when the score is $\geq 10$.

\section{Depression}

The PHQ-924 is the depression module of the Primary Care Evaluation of Mental Disorders diagnostic instrument for common mental disorders. It scores each of the nine Diagnostic and Statistical Manual of Mental Disorders, Fourth Edition criteria as " 0 " (not at all) to "3" (nearly every day). It has been validated for use in primary care and is used to make a tentative diagnosis of depression in at-risk populations, especially in those with coronary heart disease ${ }^{14}$ or stroke. ${ }^{15}$ Overall scores of $0-4,5-9,10-14,15-19$, and 20-27 are categorized as none, mild, moderate, moderately severe, and severe depression, respectively.

All questionnaires were interviewer-administered in English or Mandarin. The original English versions were translated into Mandarin. To ensure the accuracy of the translated questionnaires, a back translation to English was done by another translator who was unfamiliar with the original version. The questionnaires were administered in a standardized manner by the first, second, and third authors (VHXF, CZD, and SEMT). Interviewers strictly adhered to the administration protocol with no rephrasing allowed. A pilot study with another 5 random glaucoma patients at the glaucoma clinic was also conducted to assess the clarity of the translated questionnaires, which found that $100 \%$ of our participants could understand the questions and provide suitable responses.

\section{Statistical analysis}

Statistical analyses were performed by using the IBM SPSS for Windows (Version 21.0; IBM Corp., Armonk, NY, USA).
Data were expressed as the mean \pm SD for continuous variables and as percentages for categorical variables. Continuous variables were compared by using Student's $t$-test or one-way analysis of variance for normally distributed variables and by using the Mann-Whitney $U$-test or KruskalWallis test for skewed variables. The Pearson $\chi^{2}$ test was used for categorical variables. We examined associations of overall patient dissatisfaction in age- and gender-adjusted logistic regression models adjusted for variables that showed significance at 0.05 levels in univariate analysis. These significant variables include age, gender, race, highest education level, anxiety and depression severity, end-point mean VA (adjusting additionally for the presence of other ocular conditions, eg, cataract), and IOP. The factors associated with each of the top three domains of patient dissatisfaction with the glaucoma service were also examined, and those which showed significance at 0.05 levels in univariate analysis (data not shown) were put into separate respective logistic regression models, including end-point VA and IOP in these models.

\section{Results}

Four hundred and thirty-eight (84.6\%) of 518 patients completed the study. Eighty patients (15.4\%) were excluded as their medical records could not be retrieved. As shown in Table 1, the mean \pm SD of age of the study group was $63.46 \pm 11.02$ years (not shown in the table). Fifty-eight point six percent $(n=252)$ were male, and $82.7 \%(n=330)$ were Chinese. There were no significant differences between age, race, and gender between included versus excluded patients ( $p>0.05$ for all). The dissatisfaction rate with the overall glaucoma service was 7.5\%. Compared with satisfied patients, dissatisfied ones were more likely to have received secondary school education or above $(72.73 \%$ vs $50.4 \%, p=0.021)$, have moderate depression $(9.01 \%$ vs $3.46 \%, p=0.013)$, have moderate anxiety $(12.12 \%$ vs $3.20 \%$, $p=0.004)$, and have worse VA $(\log \mathrm{MAR}=0.41 \pm 0.43$ vs $0.27 \pm 0.49, p=0.005)$, but have lower IOP (13.55 \pm 2.46 vs 14.82 $\pm 2.86, p=0.014$; Table 1). As shown in Table 2, the three areas that received the highest dissatisfaction rates were the following: 1) explanation of test results $(24.8 \%) ; 2)$ explanation of complications in poorly controlled glaucoma (23.7\%); and 3) advice on managing glaucoma (23.5\%).

\section{Independent factors associated with dissatisfaction with glaucoma care Overall glaucoma care}

Patients with a university degree and above, compared with those with no education (odds ratio $[\mathrm{OR}]=8.06 ; 95 \%$ 
Table I Demographic, health, and ocular characteristics of the study population according to overall satisfaction with glaucoma service

\begin{tabular}{|c|c|c|c|}
\hline Patient characteristics & Satisfied $(n=405) ; 92.4 \%$ & Dissatisfied $(n=33) ; 7.6 \%$ & $p$-value \\
\hline Age, years & $63.53(10.9)$ & $63.48(11.4)$ & 0.98 \\
\hline Gender & & & 0.70 \\
\hline Male & $252(62.2)$ & $20(60.0)$ & \\
\hline Race & & & 0.78 \\
\hline Chinese & $330(81.5)$ & $27(81.8)$ & \\
\hline Malay & $38(9.4)$ & $3(9.1)$ & \\
\hline Indian/others & $37(9.1)$ & $3(9.1)$ & \\
\hline Highest education level & & & 0.021 \\
\hline No education & $72(17.8)$ & $4(12.2)$ & \\
\hline Primary education & $120(29.6)$ & $5(15.2)$ & \\
\hline Secondary school & $147(36.3)$ & $17(5 \mid .5)$ & \\
\hline Pre-university and beyond & $57(14.1)$ & $7(2 \mid .2)$ & \\
\hline Individual income, Singapore & & & 0.98 \\
\hline \multicolumn{4}{|l|}{ dollars (SGD) } \\
\hline$<\$ 1,000 /$ month & $122(30.1)$ & $10(30.3)$ & \\
\hline Marital status & & & 0.82 \\
\hline Married & $282(69.6)$ & $23(69.7)$ & \\
\hline No of self-reported medical comorbidities & $1.22 \pm 0.43$ & $1.03 \pm 0.25$ & 0.35 \\
\hline Type of glaucoma & & & 0.64 \\
\hline POAG & $195(48.2)$ & $16(48.5)$ & \\
\hline PACG/PAC & $112(27.7)$ & $6(18.2)$ & \\
\hline Secondary glaucoma & $30(7.4)$ & $5(15.2)$ & \\
\hline Ocular hypertension & $30(7.4)$ & $2(6.1)$ & \\
\hline NTG & $38(6.9)$ & $4(12.1)$ & \\
\hline Severity of glaucoma & & & 0.52 \\
\hline 0 & $39(9.6)$ & $4(12.1)$ & \\
\hline 1 & $59(14.6)$ & $3(9.1)$ & \\
\hline 2 & I8I (44.7) & $18(5.4)$ & \\
\hline$\geqq 3$ & $119(29.4)$ & $8(24.2)$ & \\
\hline Number of eye drops/eye & $1.67 \pm 0.72$ & $1.84 \pm 0.63$ & 0.22 \\
\hline Duration of follow-up, years & $5.11 \pm 1.93$ & $4.61 \pm 0.72$ & 0.54 \\
\hline Previous surgical treatment & $67(16.6)$ & $5(15.2)$ & 0.99 \\
\hline Depression & & & 0.013 \\
\hline None & $345(85.2)$ & $28(84.9)$ & \\
\hline Mild & $38(9.4)$ & I (3.0) & \\
\hline Moderate & $14(3.5)$ & $3(9.0)$ & \\
\hline Anxiety & & & 0.004 \\
\hline None & $355(87.7)$ & $26(84.9)$ & \\
\hline Mild & $29(7.2)$ & $2(6.1)$ & \\
\hline Moderate & $13(3.2)$ & $4(12.1)$ & \\
\hline Service type & & & 0.59 \\
\hline Subsidized & $302(74.9)$ & $26(78.8)$ & \\
\hline Private & $103(25.6)$ & $7(2 \mid .2)$ & \\
\hline End-point visual acuity $(\log M A R)^{a}$ & $0.27(0.5)$ & $0.41(0.4)$ & 0.005 \\
\hline Change in visual acuity (logMAR) & $0.04(0.4)$ & $0.14(0.2)$ & 0.21 \\
\hline End-point IOP $(\mathrm{mmHg})$ & $14.82(2.9)$ & $13.55(2.5)$ & 0.014 \\
\hline Change in IOP $(\mathrm{mmHg})$ & $(-3.23 \pm 4.43)$ & $(-3.42 \pm 6.28)$ & 0.81 \\
\hline
\end{tabular}

Notes: $n=438$. aExcluding patients with other ocular comorbidities. Data presented as mean (SD) or $n(\%)$.

Abbreviations: IOP, intraocular pressure; logMAR, logarithm of the minimum angle of resolution; NTG, normal tension glaucoma; PAC, primary angle closure; PACG, primary angle closure glaucoma; POAG, primary open-angle glaucoma.

$\mathrm{CI}=1.57-41.27)$, and lower end-point IOP $(\mathrm{OR}=0.83$; $95 \%$ CI $=0.71-0.98$ ) were more likely to be dissatisfied with their glaucoma care (Table 3). End-point VA was not associated with patient dissatisfaction (OR $=1.04 ; 95 \%$ $\mathrm{CI}=0.36-3.06$ ).

\section{Glaucoma test result explanation}

As shown in Table 4, patients with a monthly income between SGD1,000 and SGD2,000 (OR $=0.26 ; 95 \% \mathrm{CI}=0.12-2.77)$ and $>$ SGD10,000 (OR $=0.10 ; 95 \% \mathrm{CI}=0.01-1.39)$ were less likely to be dissatisfied with the explanation of their 
Table 2 Satisfaction areas of glaucoma care and satisfaction and dissatisfaction ratings

\begin{tabular}{lll}
\hline $\begin{array}{l}\text { Specific areas of } \\
\text { glaucoma care }\end{array}$ & $\begin{array}{l}\text { Satisfied, \% } \\
(\mathbf{n}=\mathbf{4 0 5})\end{array}$ & $\begin{array}{l}\text { Dissatisfied, \% } \\
(\mathbf{n}=\mathbf{3 3})\end{array}$ \\
\hline Clinician-patient relationship & 96.1 & 3.9 \\
Explanation of glaucoma & 93.1 & 6.9 \\
$\begin{array}{l}\text { Explanation of glaucoma test results } \\
\text { Explanation of complications in }\end{array}$ & 75.2 & 24.8 \\
$\quad 76.3$ & 23.7 \\
$\quad \begin{array}{l}\text { Advice on managing glaucoma } \\
\text { Consultation time }\end{array}$ & 76.5 & 23.5 \\
$\begin{array}{l}\text { Explanation of purpose of ocular } \\
\quad \text { hypotensives }\end{array}$ & 85.9 & 14.1 \\
$\begin{array}{l}\text { Overall satisfaction with glaucoma } \\
\text { service }\end{array}$ & 84.2 & 15.8 \\
\hline
\end{tabular}

test results, compared with those with a monthly income of $<$ SGD1,000.

\section{Glaucoma complications explanation}

Compared with satisfied patients, patients who were slightly older (OR $=1.03 ; 95 \% \mathrm{CI}=1.01-1.06)$ were more likely to be

Table 3 Factors associated with overall patient dissatisfaction with their glaucoma care

\begin{tabular}{|c|c|c|c|}
\hline Variables & Adjusted OR & $95 \% \mathrm{Cl}$ & $p$-value \\
\hline Age & 1.01 & $(0.99-1.06)$ & 0.24 \\
\hline \multicolumn{4}{|l|}{ Gender } \\
\hline Male & I & 1 & I \\
\hline Female & 0.95 & $(0.43-2.10)$ & 0.95 \\
\hline \multicolumn{4}{|l|}{ Race } \\
\hline Chinese & I & I & I \\
\hline Malay & 0.70 & $(0.15-3.52)$ & 0.63 \\
\hline Indian/others & 1.91 & $(0.55-6.59)$ & 0.31 \\
\hline \multicolumn{4}{|l|}{ Education } \\
\hline None & I & $\mathrm{I}$ & I \\
\hline Primary & 1.05 & $(0.23-4.77)$ & 0.95 \\
\hline Secondary & 2.94 & $(0.78-11.03)$ & 0.11 \\
\hline Pre-university & 1.07 & $(0.15-7.63)$ & 0.95 \\
\hline University and higher & 8.06 & $(1.57-41.27)$ & 0.01 \\
\hline \multicolumn{4}{|l|}{ Anxiety } \\
\hline None & I & I & I \\
\hline Mild & 0.29 & $(0.03-2.87)$ & 0.29 \\
\hline Moderate or worse & 1.15 & $(0.15-9.00)$ & 0.89 \\
\hline \multicolumn{4}{|l|}{ Depression } \\
\hline None & 1 & I & I \\
\hline Mild & 0.97 & $(0.14-6.63)$ & 0.97 \\
\hline Moderate or worse & 4.62 & $(0.77-27.92)$ & 0.10 \\
\hline End-point VA & 1.04 & $(0.36-3.06)$ & 0.94 \\
\hline Other ocular comorbidities & 2.15 & $(0.98-4.72)$ & 0.06 \\
\hline End-point IOP & 0.83 & $(0.7 I-0.98)$ & 0.02 \\
\hline
\end{tabular}

Notes: All regression coefficients are derived from a single logistic regression model with patient dissatisfaction as the dependent variable, adjusted for age, gender, ethnicity, highest education level, anxiety and depression severity, end-point VA, other ocular comorbidities (four big groups of cataract, age-related macular degeneration, diabetic retinopathy, and corneal diseases), and end-point IOP.

Abbreviations: IOP, intraocular pressure; OR, odds ratio; VA, visual acuity.
Table 4 Factors associated with patient dissatisfaction with explanation of glaucoma test results

\begin{tabular}{|c|c|c|c|}
\hline Variables & Adjusted OR & $95 \% \mathrm{Cl}$ & $p$-value \\
\hline Age & 1.01 & $(1.00-1.04)$ & 0.31 \\
\hline \multicolumn{4}{|l|}{ Gender } \\
\hline Male & I & 1 & $\mathrm{I}$ \\
\hline Female & 0.75 & $(0.45-1.24)$ & 0.79 \\
\hline \multicolumn{4}{|l|}{ Race } \\
\hline Chinese & I & 1 & $\mathrm{I}$ \\
\hline Malay & 0.68 & $(0.26-1.80)$ & 0.95 \\
\hline Indian/others & 1.02 & $(0.42-2.46)$ & 0.34 \\
\hline \multicolumn{4}{|l|}{ Education } \\
\hline None & I & 1 & I \\
\hline Primary & 0.68 & $(0.32-1.45)$ & 0.32 \\
\hline Secondary & 1.33 & $(0.67-2.64)$ & 0.41 \\
\hline Pre-university & 1.07 & $(0.38-3.00)$ & 0.90 \\
\hline $\begin{array}{l}\text { University and higher } \\
\text { Income, Singapore }\end{array}$ & 1.33 & $(0.38-4.72)$ & 0.66 \\
\hline dollars (SGD) & I & I & 1 \\
\hline$<\$ 1,000 /$ month & 0.26 & $(0.12-2.77)$ & 0.002 \\
\hline$\$ 1,000$ to $<\$ 2,000$ & 0.48 & $(0.16-8.46)$ & 0.05 \\
\hline$\$ 2,000$ to $<\$ 4,000$ & 0.42 & $(0.16-1.05)$ & 0.05 \\
\hline$\$ 4,000$ to $<\$ 10,000$ & 0.10 & $(0.01-1.39)$ & 0.04 \\
\hline \multicolumn{4}{|l|}{$>\$ 10,000$} \\
\hline \multicolumn{4}{|l|}{ Service type } \\
\hline Subsidized & I & I & I \\
\hline Private & 0.56 & $(0.27-I .14)$ & 0.56 \\
\hline End-point VA & 1.30 & $(0.74-2.29)$ & 0.37 \\
\hline Other ocular comorbidities & 0.90 & $(0.76-2.30)$ & 0.38 \\
\hline End-point IOP & 0.97 & $(0.89-1.06)$ & 0.49 \\
\hline
\end{tabular}

Notes: All regression coefficients are derived from a single logistic regression model with patient dissatisfaction as the dependent variable, adjusted for age, gender, ethnicity, highest education level, income, service type, end-point VA, other ocular comorbidities, and end-point IOP.

Abbreviations: IOP, intraocular pressure; OR, odds ratio; VA, visual acuity.

dissatisfied with the explanation of glaucoma complications (Table 5). Compared with those from the subsidized service, patients from the private service of SNEC (OR $=0.33 ; 95 \%$ $\mathrm{CI}=0.17-0.64)$ were less likely to be dissatisfied with the explanation of glaucoma complications.

\section{Glaucoma management advice}

Compared with patients with a subsidized service, patients from the private service $(\mathrm{OR}=0.35 ; 95 \% \mathrm{CI}=0.18-0.64$ ) were also less likely to be dissatisfied with the glaucoma management advice given to them (Table 6). Mean VA or IOP was not associated with patient dissatisfaction with test result explanation, glaucoma complications explanation, and glaucoma management advice ( $p>0.05$ for all; Tables 4-6).

\section{Discussion}

This is the first study to evaluate patient dissatisfaction with a glaucoma tertiary service and the associated independent risk factors. Although the patient dissatisfaction rate with the overall glaucoma service in the largest tertiary eye hospital in 
Table 5 Factors associated with patient dissatisfaction with explanation of glaucoma complications

\begin{tabular}{|c|c|c|c|}
\hline Variables & Adjusted OR & $95 \% \mathrm{Cl}$ & $p$-value \\
\hline Age & 1.03 & $(1.01-1.06)$ & 0.01 \\
\hline \multicolumn{4}{|l|}{ Gender } \\
\hline Male & 1 & I & I \\
\hline Female & 0.98 & $(0.60-1.59)$ & 0.93 \\
\hline \multicolumn{4}{|l|}{ Race } \\
\hline Chinese & I & I & 1 \\
\hline Malay & 0.88 & $(0.37-2.1 I)$ & 0.95 \\
\hline Indian/others & 1.40 & $(0.60-3.28)$ & 0.44 \\
\hline \multicolumn{4}{|l|}{ Education } \\
\hline None & I & 1 & I \\
\hline Primary & 0.65 & $(0.31-1.35)$ & 0.24 \\
\hline Secondary & 1.03 & $(0.53-2.00)$ & 0.93 \\
\hline Pre-university & $\mathrm{I} .44$ & $(0.56-3.7 I)$ & 0.45 \\
\hline University and higher & 1.07 & $(0.33-3.50)$ & 0.92 \\
\hline \multicolumn{4}{|l|}{ Service type } \\
\hline Subsidized & I & I & 1 \\
\hline Private & 0.33 & $(0.17-0.64)$ & 0.001 \\
\hline End-point VA & 1.46 & $(0.91-2.34)$ & 0.25 \\
\hline Other ocular comorbidities & 1.30 & $(0.79-2.13)$ & 0.47 \\
\hline End-point IOP & 0.97 & $(0.89-1.05)$ & 0.47 \\
\hline
\end{tabular}

Notes: All regression coefficients are derived from a single logistic regression model with patient dissatisfaction as the dependent variable, adjusted for age, gender, ethnicity, highest education level, anxiety and depression severity, illness coherence, end-point VA, other ocular comorbidities, and end-point IOP.

Abbreviations: IOP, intraocular pressure; OR, odds ratio; VA, visual acuity.

Table 6 Factors associated with patient dissatisfaction with glaucoma management advice

\begin{tabular}{|c|c|c|c|}
\hline Variables & Adjusted OR & $95 \% \mathrm{Cl}$ & $p$-value \\
\hline Age & 1.02 & $(1.00-1.05)$ & 0.05 \\
\hline \multicolumn{4}{|l|}{ Gender } \\
\hline Male & I & I & 1 \\
\hline Female & 0.93 & $(0.57-I .5 I)$ & 0.77 \\
\hline \multicolumn{4}{|l|}{ Race } \\
\hline Chinese & I & I & I \\
\hline Malay & 0.99 & $(0.42-2.33)$ & 0.99 \\
\hline Indian/others & $\mathrm{I} .4 \mathrm{I}$ & $(0.60-3.30)$ & 0.44 \\
\hline \multicolumn{4}{|l|}{ Education } \\
\hline None & I & I & I \\
\hline Primary & 1.02 & $(0.49-2.30)$ & 0.96 \\
\hline Secondary & 1.97 & $(1.10-4.51)$ & 0.06 \\
\hline Pre-university & 2.54 & $(0.99-6.87)$ & 0.06 \\
\hline University and higher & 1.68 & $(0.7 I-7.25)$ & 0.40 \\
\hline \multicolumn{4}{|l|}{ Service type } \\
\hline Subsidized & I & I & 1 \\
\hline Private & 0.35 & $(0.18-0.64)$ & 0.001 \\
\hline End-point VA & 1.32 & $(0.50-2.22)$ & 0.26 \\
\hline Other ocular comorbidities & 1.02 & & 0.94 \\
\hline End-point IOP & 0.95 & $(0.80-3.80)$ & 0.20 \\
\hline
\end{tabular}

Notes: All regression coefficients are derived from a single logistic regression model with patient satisfaction as the dependent variable, adjusted for age, gender, ethnicity, highest education level, service type, other ocular conditions (four big groups of cataract, age-related macular degeneration, diabetic retinopathy, and corneal diseases), and end-point VA.

Abbreviations: IOP, intraocular pressure; OR, odds ratio; VA, visual acuity.
Singapore was relatively low ( $~ 8 \%)$, up to a quarter of these patients were dissatisfied with three specific areas of care, namely understanding of glaucoma test results, glaucoma complications, and disease management. We found that a higher education level and a lower IOP, ironically, but not VA, were associated with overall patient dissatisfaction. These findings suggest potential areas for interventions likely to improve patient satisfaction with their glaucoma care.

There are no earlier studies available for comparison of results with our study. We report a low dissatisfaction rate with our glaucoma service of $\sim 8 \%$ in our population. Dissatisfaction rates of patients with other chronic diseases such as type 2 diabetes, ${ }^{8,9,25}$ ischemic heart disease, ${ }^{26}$ chronic obstructive lung disease, ${ }^{26}$ and with anesthetic practices ${ }^{27}$ have higher rates of dissatisfaction ranging from $20 \%$ to $30 \%$. From our study, understanding of glaucoma test results, complications, and disease management scored higher dissatisfaction rates compared with the areas of patient time spent per consultation with clinician and patient-clinician rapport. These three areas of dissatisfaction represent gaps in patients' glaucoma knowledge, which add to the commonly identified gaps specified in literature. A survey of ophthalmic literature on patients' glaucoma knowledge revealed that between $5 \%$ and $56 \%$ of patients gave satisfactory answers on the cause of glaucoma. ${ }^{28} \mathrm{~A}$ multicentered study in the Netherlands showed that $50 \%$ of glaucoma patients had $\leq 49 \%$ of correct answers on glaucoma knowledge, ${ }^{29}$ amid one of the handful of studies revealing poor knowledge on glaucoma. ${ }^{30-34}$ Hence, our study reinforces what is known in current literature that patient education is an essential component of derived satisfaction with patients' providers, as found in a study with patients with ischemic heart disease and chronic obstructive lung disease. ${ }^{26} \mathrm{~A}$ poor understanding of glaucoma has also been associated with the problem of low adherence or dropout from glaucoma treatment. ${ }^{35-38}$ Thus, glaucoma clinicians could seek to improve patients' understanding in these specific areas, as this may lead to improved satisfaction and better glaucoma follow-up and medication adherence rates in the long run. However, an earlier study also found no association between glaucoma knowledge and adherence to medication. ${ }^{38}$

Our study found that a lower IOP, ironically, and patient education levels, but not VA or severity of glaucoma, were associated with overall glaucoma dissatisfaction. Theoretically, with a poor understanding of glaucoma management, complications, and implications of test results, patients may not understand the importance of adherence to their eye 
drop regimen. Nonadherence can increase the likelihood of patients being prescribed multiple eye drops to better control IOP. It is an unfortunate cycle for the patient as they would be less satisfied at each consultation when receiving bad news of their worsening condition, reinforcing patients' dissatisfaction. Surprisingly, our study showed that a lower IOP was associated with a higher glaucoma dissatisfaction and does not support the view that greater patient satisfaction might be associated with better clinical outcomes. No other study has reported the associations of glaucoma satisfaction with visual and disease outcomes such as IOP, VA, and glaucoma severity.

Other studies have also reported that a higher education level, similar to ours, is associated with poor patient satisfaction with health services in general. ${ }^{39,40}$ With a higher education level, the population is likely to have better income, social status, and higher expectations of health services received. In terms of difference in service, private patients in our study were less dissatisfied with the explanation of glaucoma complications and management of disease advice. This is likely due to the greater amount of time and personalized attention the clinicians provide to private patients versus those on subsidized care. Future studies could possibly evaluate further the relationship between the length of consultation and patient satisfaction.

Several measures could be proposed to improve patient satisfaction with specific glaucoma domains of care. For example, glaucomatologists could use test formats that may provide a better visual representation of the optic nerve or visual field abnormalities compared with those with numerical outputs of the retinal nerve fiber layer thickness to improve the understanding of test. With a high patient load, glaucoma understanding could be enhanced beyond the consultation period with leaflet distribution, broadcasting of short educational clips, and service from specialized glaucoma nurses. Further prospective studies could evaluate proposed patient education measures and their effectiveness in increasing patient satisfaction levels. A US-based telemedicine program targeted at at-risk glaucoma patients showed an increase in knowledge and attitudes toward glaucoma care postintervention, supporting telemedicine as a possible effective model of glaucoma care delivery. ${ }^{41}$ Other potential measures to improve patient education include smart phone technology and intensive, individualized educational session. ${ }^{42,43}$

The strengths of this study include the large sample size and recruitment from the largest tertiary eye center in Singapore and the use of a new multidimensional glaucoma satisfaction survey covering various glaucoma service aspects to evaluate patient satisfaction. However, the study has several limitations. First, it is cross-sectional study, and we are unable to infer causality on any of the reported associations. Second, participants could have answered to "please" the interviewer, and while participants were reassured before the start of survey of the anonymity and confidentiality of their information, some may not be forthcoming in revealing dissatisfaction as they might suspect it could affect their subsequent treatment. These could largely contribute to the low appearing rate of dissatisfaction in our Asian population. We did not include the domain on satisfaction with "medications," as we felt that the nature of medication itself had a separate bearing on satisfaction therapy which was nonmodifiable in nature compared with the other domains surveyed in our study such as patient-clinician rapport and explanation of glaucoma tests.

\section{Conclusion}

Less than one tenth of glaucoma patients were dissatisfied with their overall glaucoma service. A lower IOP, ironically, and a higher education level were associated with greater overall dissatisfaction, but not VA or glaucoma severity. Three areas in particular received relatively high dissatisfaction levels. Patients with lower income were less likely to be dissatisfied with the explanation of glaucoma test results. Those under the private service were also less likely to be dissatisfied with the explanation of glaucoma complications and management advice given to them. Clinicians could focus on improving patients' understanding of their various glaucoma test results, glaucoma complications, and disease management, which could potentially increase patient satisfaction levels. Future prospective studies could evaluate whether implemented measures that increase patients' understanding of glaucoma ultimately lead to better visual outcomes in patients.

\section{Acknowledgment}

This study was supported by the Singapore National Eye Centre Health Research Endowment Fund 2014.

\section{Disclosure}

The authors report no conflicts of interest in this work.

\section{References}

1. Quigley HA, Broman AT. The number of people with glaucoma worldwide in 2010 and 2020. Br J Ophthalmol. 2006;90(3):262-267.

2. Kravitz R. Patient satisfaction with health care: critical outcome or trivial pursuit? J Gen Int Med. 1998;13(4):280-282.

3. Oliver RL. Satisfaction: A Behavioral Perspective on the Consumer. New York: McGraw-Hill; 1996. 
4. Ware JE Jr, Snyder MK, Wright WR, Davies AR. Defining and measuring patient satisfaction with medical care. Eval Program Plann. 1983; 6(3-4):247-263.

5. Manary MP, Boulding W, Staelin R, Glickman SW. The patient experience and health outcomes. N Engl J Med. 2013;368(3):201-203.

6. Pascoe GC. Patient satisfaction in primary health care: a literature review and analysis. Eval Program Plann. 1983;6:185-210.

7. Williams B. Patient satisfaction: a valid concept? Soc Sci Med. 1994;38: 509-516.

8. Redekop WK, Koopmanschap MA, Stolk RP, Rutten GE, Wolffenbuttel BH, Niessen LW. Health-related quality of life and treatment satisfaction in Dutch patients with type 2 diabetes. Diabetes Care. 2002;25:458-463.

9. Alazri MH, Neal RD. The association between satisfaction with services provided in primary care and outcomes in Type 2 diabetes mellitus. Diabet Med. 2003;20:486-490.

10. Ali S, Chessex C, Bassett-Gunter R, Grace SL. Patient satisfaction with cardiac rehabilitation: association with utilization, functional capacity, and heart-health behaviors. Patient Prefer Adherence. 2017;11:821-830.

11. Petterson T, Lee P, Hollis S, Young B, Newton P, Dornan T. Well-being and treatment satisfaction in older people with diabetes. Diabetes Care. 1998;21:930-935.

12. Yeaw J, Benner JS, Walt JG, Sian S, Smith DB. Comparing adherence and persistence across 6 chronic medication classes. J Manag Care Pharm. 2009;15(9):728-740.

13. Quigley HA. Improving eye drop treatment for glaucoma through better adherence. Optom Vis Sci. 2008;85(6):374-375.

14. Haynes RB, McDonald HP, Garg AX. Helping patients follow prescribed treatment: clinical applications. JAMA. 2002;288(22):2880-2883.

15. Kerr NM, Patel HY, Chew SS, Ali NQ, Eady EK, Danesh-Meyer HV. Patient satisfaction with topical ocular hypotensives. Clin Exp Ophthalmol. 2013;41(1):27-35.

16. Day DG, Sharpe ED, Atkinson MJ, Stewart JA, Stewart WC. The clinical validity of the treatment satisfaction survey for intraocular pressure in ocular hypertensive and glaucoma patients. Eye (Lond). 2006;20(5): 583-590.

17. Sleath B, Robin AL, Covert D, Byrd JE, Tudor G, Svarstad B. Patientreported behavior and problems in using glaucoma medications. Ophthalmology. 2006;113(3):431-436.

18. Zimmerman TJ, Hahn SR, Gelb L, Tan H, Kim EE. The impact of ocular adverse effects in patients treated with topical prostaglandin analogs: changes in prescription patterns and patient persistence. J Ocul Pharmacol Ther. 2009;25(2):145-152.

19. Muñoz Negrete FJ, Lemij HG, Erb C. Switching to preservative-free latanoprost: impact on tolerability and patient satisfaction. Clin Ophthalmol. 2017;11:557-566.

20. Glen FC, Baker H, Crabb DP. A qualitative investigation into patients' views on visual field testing for glaucoma monitoring. BMJ Open. 2014;4:e003996.

21. Mills RP, Budenz DL, Lee PP, et al. Categorizing the stage of glaucoma from pre-diagnosis to end-stage disease. Am J Ophthalmol. 2006;141: 24-30.

22. Mabuchi F, Yoshimura K, Kashiwagi K, et al. High prevalence of anxiety and depression in patients with primary open-angle glaucoma. J Glaucoma. 2008;17(7):552-557.

23. Spitzer RL, Kroenke K, Williams JB, Lowe B. A brief measure for assessing generalized anxiety disorder: the GAD-7. Arch Intern Med. 2006; 166(10):1092-1097.

24. Santos IS, Tavares BF, Munhoz TN, et al. Sensibilidade e especificidade do Patient Health Questionnaire-9 (PHQ-9) entre adultos da população geral. [Sensitivity and specificity of the Patient Health Questionnaire-9 (PHQ-9) among adults from the general population]. Cad Saúde Pública. 2013;29:1533-1543. Portuguese.
25. Wredling R, Stalhammar J, Adamson U, Berne C, Larsson Y, Ostman J. Well-being and treatment satisfaction in adults with diabetes: a Swedish population-based study. Qual Life Res. 1995;4:515-522.

26. Fan VS, Reiber GE, Diehr P, Burman M, McDonell MB, Fihn SD. Functional status and patient satisfaction: a comparison of ischemic heart disease, obstructive lung disease, and diabetes mellitus. J Gen Intern Med. 2005;20(5):452-459.

27. Gebremedhn EG, Chekol WB, Amberbir WD, Flatie TD. Patient satisfaction with anaesthesia services and associated factors at the University of Gondar Hospital, 2013: a cross-sectional study. BMC Res Notes. 2015;8:377.

28. Deokule S, Sadiq S, Shah S. Chronic open angle glaucoma: patient awareness of the nature of the disease, topical medication, compliance and the prevalence of systemic symptoms. Ophthalmic Physiol Opt. 2004; 24(1):9-15.

29. Hoevenaars JG, Schouten JS, van den Borne B, Beckers HJ, Webers CA. Knowledge base and preferred methods of obtaining knowledge of glaucoma patients. Eur J Ophthalmol. 2005;15(1):32-40.

30. Lunnela J, Kaariainen M, Kyngas H. Adherence of Finnish people with glaucoma to treatment plans and connected factors. Int J Circumpolar Health. 2011;70(1):79-89.

31. Peralta E, Muir KW, Rosdahl JA. Systematic review of knowledge assessments for glaucoma patients. Semin Ophthalmol. 2016;14: $1-12$.

32. Mansouri K, Iliev ME, Rohrer K, Shaarawy T. Compliance and knowledge about glaucoma in patients at tertiary glaucoma units. Int Ophthalmol. 2011;31(5):369-76.

33. Elliott AJ. Glaucoma: ignorance and apathy. Eye (Lond). 1989;3(Pt 4): 485-486.

34. Ung C, Zhang E, Alfaro T. Glaucoma severity and medication adherence in a county hospital population. Ophthalmology. 2013;120(6): 1150-1157.

35. Robin A, Grover DS. Compliance and adherence in glaucoma management. Indian J Ophthalmol. 2011;59(Suppl):S93-S96.

36. Danesh-Meyer HV, Deva NC, Slight C, et al. What do people with glaucoma know about their condition? A comparative cross-sectional incidence and prevalence survey. Clin Exp Ophthalmol. 2008;36(1): $13-18$.

37. Gray TA, Fenerty C, Harper R, et al. Preliminary survey of educational support for patients prescribed ocular hypotensive therapy. Eye (Lond). 2010;24(12):1777-1778.

38. Costa VP, Spaeth GL, Smith M, Uddoh C, Vasconcellos JP, Kara-Jose N. Patient education in glaucoma: what do patients know about glaucoma? Arq Bra Oftalmol. 2006;69(6):923-927.

39. Hargraves JL, Wilson IB, Zaslavsky A, et al. Adjusting for patient characteristics when analyzing reports from patients about hospital care. Med Care. 2001;39:635-641.

40. Birhanu Z, Assefa T, Woldie M, Morankar S. Determinants of satisfaction with health care provider interactions at health centres in central Ethiopia: a cross sectional study. BMC Health Serv Res. 2010;10:78.

41. Rhodes LA, Huisingh CE, McGwin G, et al. Eye Care Quality and Accessibility Improvement in the Community (EQUALITY): impact of an eye health education program on patient knowledge about glaucoma and attitudes about eye care. Patient Relat Outcome Meas. 2016; 7:37-48.

42. Gray TA, Fenerty C, Harper R, et al. Individualised patient care as an adjunct to standard care for promoting adherence to ocular hypotensive therapy: an exploratory randomised controlled trial. Eye (Lond). 2012;26:407-417.

43. Okeke CO, Quigley HA, Jampel HD, et al. Interventions improve poor adherence with once daily glaucoma medications in electronically monitored patients. Ophthalmology. 2009;116(2):2286-2293. 


\section{Supplementary material}

\section{Glaucoma Satisfaction Survey (Kindly tick the best option)}

How satisfied are you with ...

(1) The way your glaucoma doctor treats you during each visit?

(2) The explanation of what glaucoma is given by your glaucoma doctor?

(3) The explanation of your test results given by your glaucoma doctor?

(4) The explanation of the complications of glaucoma, if not well-controlled, by your glaucoma doctor?

(5) The advice given by your glaucoma doctor on how to manage your glaucoma?

(6) The amount of time your glaucoma doctor spends with you?

(7) The explanation of the purpose of eyedrops given by your glaucoma doctor?

(8) The overall glaucoma care you have received?

Figure SI Glaucoma Satisfaction Survey.

\section{Publish your work in this journal}

Clinical Ophthalmology is an international, peer-reviewed journal covering all subspecialties within ophthalmology. Key topics include: Optometry; Visual science; Pharmacology and drug therapy in eye diseases; Basic Sciences; Primary and Secondary eye care; Patient Safety and Quality of Care Improvements. This journal is indexed on

Submit your manuscript here: http://www.dovepress.com/clinical-ophthalmology-journal
Dovepress

PubMed Central and CAS, and is the official journal of The Society of Clinical Ophthalmology (SCO). The manuscript management system is completely online and includes a very quick and fair peer-review system, which is all easy to use. Visit http://www.dovepress.com/ testimonials.php to read real quotes from published authors. 